\title{
Improved HFACS on Human Factors of Construction Accidents: A China Perspective
}

\author{
Gui Ye $\mathbb{D}^{\text {, }}$, Qin Tan, Xiaoli Gong, Qingting Xiang, Yuhe Wang, and Qinjun Liu \\ School of Construction Management and Real Estate, Chongqing University, 83 Shabei St., Chongqing 400045, China \\ Correspondence should be addressed to Gui Ye; yegui760404@126.com
}

Received 20 April 2018; Revised 30 May 2018; Accepted 13 June 2018; Published 18 July 2018

Academic Editor: Xianbo Zhao

Copyright $\odot 2018$ Gui Ye et al. This is an open access article distributed under the Creative Commons Attribution License, which permits unrestricted use, distribution, and reproduction in any medium, provided the original work is properly cited.

\begin{abstract}
Human errors are one of the major contributors of accidents. In order to improve the safety performance, human errors have to be addressed. Human Factors Analysis and Classification System (HFACS) has been developed as an analytical framework for the investigation of the role of human errors in aviation accidents. However, the HFACS framework did not reveal the relationships describing the effect among diverse factors at different levels. Similarly, its interior structure was not exposed. As a result, it is difficult to identify critical paths and key factors. Therefore, an improved Human Factors Analysis and Classification System in the construction industry (I-HFACS) was developed in this study. An analytical I-HFACS mechanism was designed to interpret how activities and decisions made by upper management lead to operator errors and subsequent accidents. Critical paths were highlighted. Similarly, key human factors were identified, that is, "regulatory factors," "organizational process," "supervisory violations," "adverse spiritual state," "skill underutilization," "skill-based errors," and "violations." Findings provided useful references for the construction industry to improve the safety performance.
\end{abstract}

\section{Introduction}

Construction work is highly associated with safety hazards. In America, fatal injuries of the private construction sector were 937 in 2015, with 4 percent rise, which was the highest since 2008, ranking first among the 16 industry sectors [1]. In Britain, the rate of fatal injuries in the construction industry was more than 3.5 times the average mortality rate in all sectors in 2015 [2]. This is especially a major concern in developing countries [3]. According to the Ministry of Housing and Urban-Rural Development of the People's Republic of China (MOHURD), the new building area in China is more than 2 billion square meters, being the largest in the world. In 2016, the number of construction accidents in China rose $124.8 \%$ to 3523 . This has shown that the safety in construction activities is severe and a significant challenge in China.

Health and Safety Executives concluded that human errors were responsible for over 80 percent of accidents [4]. Human errors were generally defined as “. . . situations where a sequence of planned events of spiritual or physical activities haven't been able to achieve the desired outcomes, and we can't attribute these failures to the intervention of some change agency" [5]. It is well recognized that human errors should be paid attention to in construction projects [6]. By settling human errors, statistics on accidents cases, injuries, and deaths in the construction sector are expected to be decreased [7].

There are two aspects of human errors-related issues [8]: the individual approach and systematic approach. Traditionally, the individual approach focuses on unsafe acts, which are viewed as resulting primarily from abnormal psychological issues such as lack of attention, negligence, carelessness, shortage of motivation, and recklessness. The systematic approach [9] views human errors as a consequence, rather than a cause. In the systematic approach, human errors have roots not lying in the aberration of human nature but in "upstream and latent" factors of the system $[8,10]$. Compared to the systematic approach, the individual approach does not carry out the analysis of mishaps and near misses in detail. As a result, recurrent error traps will not be uncovered until 
TABLE 1: Types of human-related accident analysis methods [31].

\begin{tabular}{lcc}
\hline & Provision of a set of causal factors & No provision of a set of causal factors \\
\hline Micro & Type II (e.g., HPES, K-HPES, HPIP, & Type I (e.g., root cause analysis techniques such as \\
(Partly) meso and micro & CREAM, SOL, TRACEr, and HFIT) & factor charting) \\
Meso and micro & Type IV (e.g., HFACS) \\
Macro and meso and micro & & Type III (e.g., AcciMap and STAMP) \\
\hline
\end{tabular}

the occurrence. Similarly, by revolving around the individual sources of human errors, the individual approach segregates unsafe acts from the systematic environment [8].

Therefore, the system approach should be adopted to examine human errors for the construction safety improvement [11]. Wiegmann and Shappell suggested that HFACS (Human Factors Analysis and Classification System), which was initially developed for aviation, was an open tool of systematic analysis and should be adjusted according to specific characteristics of different industries [12]. However, Dekker suggested there were some confusions between classification and analysis in HFACS. The simple categorization of failures does not have explanatory and persuasive power [10]. It is necessary to find the impact mechanism and interior structure of this framework. What is more, construction projects are resource-consuming. Constrained by limited resources, managers and researchers have devoted to effective allocation and utilization of resources [13]. To solve the distribution problem with limited resources, it is essential to identify critical paths, key factors, and priorities for managers [14]. Therefore, the aims of this study are (1) to develop the modified and improved HFACS within the Chinese construction industry context and identify the impact mechanism and interior structure of it and (2) to identify the critical paths and key human factors affecting high frequency of occurrence of accidents in the construction industry based on this model.

\section{Literature Review}

Previous studies have examined factors of safety accidents from various perspectives. Chiu and Hsieh pointed out that human errors may be divided into two types: active human errors and latent human errors [15]. In 1950, Heinrich et al. advocated that accidents were caused by unsafe acts and unsafe conditions [16]. Motivated by this idea, construction safety management has concentrated on eliminating both areas [17]. Unsafe acts have been recognized as the direct and active reason for construction accidents [18]. As unsafe acts are often intentional, cognitive theory aimed to explain human acts by understanding thought processes [19]. A few notable research studies on workers' spiritual processes were taken towards unsafe acts, such as attitudes towards behaviors and risk perception [20].

Reason clearly indicated that, in the most cases, unsafe acts (active human errors) were influenced by latent conditions before producing a loss [21]. Many research studies have investigated different working conditions and identified condition risk factors in construction projects influencing unsafe acts $[22,23]$, such as inappropriate ground conditions and an unacceptably noisy or crowded environment [24, 25]. And Krivit et al. also suggested that most unsafe acts could also be traced back to supervision [26]. Meliá and Becerril demonstrated that factors related to the supervisors were cited by workers as important causes of their occupational stress in the construction sector [27]. Indeed, evidence has shown that organizational factors shaped the context that contributes to human errors [28]. Khosravi et al. identified the organizational factors, including policy and plan, safety climate and culture, project and job design, and resource management, having high evidence of associations with unsafe acts in the construction sector [29].

A critical review of the previous studies of human errors showed that these various "upstream and latent" factors (e.g., site conditions, supervisions, and organizational factors) contributed to human errors. While these active and latent human errors are recognized related and intermingled, they were examined separately from one another in practice and did not provide a holistic framework that may help project managers handle the various policy, process, and personnel aspects that may affect construction safety [30].

A number of human-related accident analysis methods have been developed to assist in comprehending how human errors occur. Yoon et al. classified these methods into four types in Table 1 by two criteria [31]. Reviewing human-related methods, we found HFACS (Human Factors Analysis and Classification System) provided a predetermined set of causal factors by incorporating various "upstream and latent" factors. Wiegmann and Shappell argued that HFACS had advantages of diagnosis, reliability, and comprehensiveness, particularly in large-scale and complex accidents [12]. One advantage of HFACS is its use of generic terms and descriptors that are applicable to a range of industries. However, HFACS was initially developed for aviation and the definition of each term may be diverse according to different industries. Many recent studies have evaluated the effectiveness of HFACS in various safety-critical domains which were aviation [32], navigation [33], coal mine [34], railway [35], and so on. Thus, HFACS provides a useful tool for analyzing human factors of construction accidents and can be adjusted and improved according to specific characteristics of the construction industry.

The fundamentals of HFACS lied in the theory of Reason's GEMS which was often referred to as the "Swiss cheese model" [36]. GEMS depicted errors as arising from holes at four levels, beginning with the operator, and working up through the system to organizational conditions [36]. According to this model, active failures combine with latent conditions upstream in the organization to lead to an accident. Active factors occur just before the accident and have 
traditionally been most often cited as the cause of an accident. Latent factors often exist for years and may never be associated with an accident or identified as a safety issue, unless they are explicitly examined [36]. The advantage of this model is bringing these human errors together into a systematic and integrated framework. However, "Swiss cheese model" did not explain the exact meaning of the "hole" in the cheese; that is, there was no illustration of what the defects of each level were. To remedy this, Wiegmann and Shappell developed HFACS, in which unsafe acts were produced by a group of underlying and potential factors of the unsafe precondition and unsafe supervision and organization [37]. Unsafe acts were active factors, involving violations and errors. The preconditions draw a picture of the substandard and aberrant conditions and performances of operators. Unsafe supervision traced the cause-effect chain of events spawning unsafe acts up to front-line supervisors. Organizational influences involved failures in activities and decisions made by the upper management that had an impact on the performance of the supervision, along with preconditions and operations of workers.

In the construction industry, Hale et al. have proposed an extended HFACS framework based on a study of a small sample reported from the UK Health and Safety Executive [38]. However, that study did not reveal the relationships among diverse factors at different levels and identify critical paths and key factors in the proposed framework. First, the traditional HFACS has a few limitations. Dekker suggested that the framework merely repositioned human errors by shifting them from the forefront to higher up in the organization instead of finding solutions for them [10]. To remedy this, several studies have revealed the relationships describing the effect among diverse factors at different levels in the framework [39]. However, they did not explain whether the factors at the same level may also be associated. Second, it is well known that a construction project is the process of resource consumption. Especially for large projects, the type of consumption of resources is various and the quantities are large [13]. The process of the resource allocation seeks to find an optimal allocation of a limited amount of resources to a number of tasks for optimizing their objectives subject to the given resource constraint. During the construction process, the project cannot be sustained to meet the various requests for resources due to the interference of various uncertain factors. The limitedresource allocation problem arises in many construction projects when there are different limitations on the amount of resources available to the managers [14]. It is significant to rationally make use of the resources in the construction process and allocate the resources in the key areas that can raise the level of safety [40]. To solve the distribution problem with limited resources, the objective is to assign priorities to the project activities based on measures obtained from the critical paths and key factors [14].

\section{Methodology}

3.1. Research Design. Figure 1 shows the research process and methods in this study. The entire research process consisted of two steps: in stage-1, the initial HFACS framework in the

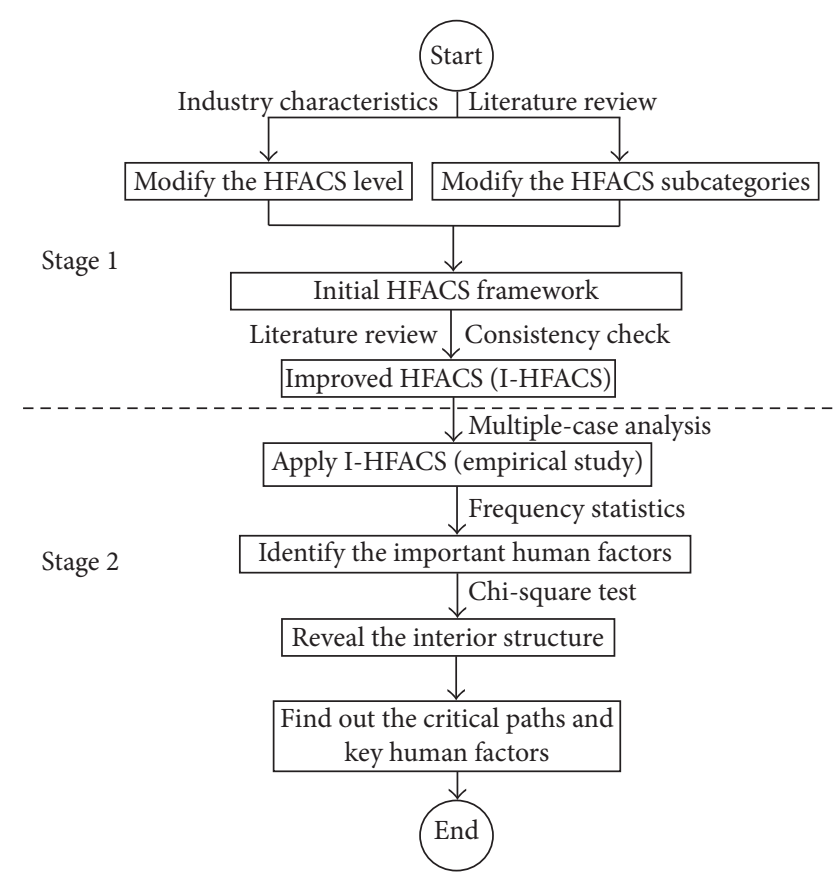

Figure 1: The research framework.

construction industry was developed through modifying the HFACS level and subcategories based on a critical review of existing studies. Consequently, a literature review was carried out to identify the definition and specific performance of each subcategory based on the initial HFACS framework, and consistency check was done to confirm the final improved HFACS framework (I-HFACS). Then, in stage-2, an empirical study of 150 accident cases (the selection of 150 sample cases is shown in Section 3.3.1) was conducted to collect data applying the I-HFACS framework. Subsequently, frequency analysis was undertaken to identify the relatively important human factors. Lastly, reviewing available statistical tests (as seen in Table 2), the chi-square test was selected to test the associations between the subcategories at the adjacent levels and the same levels because of the binomial data in this study. Thus, the chi-square test was conducted to reveal the interior structure. Based on the important human factors identified in frequency analysis and the associations between subcategories, we could further identify the critical paths and key human factors.

3.2. Consistency Check. Olsen and Shorrock suggested that different observers may have inconsistent ideas in the same phenomenon among themselves [42]. Meanwhile, there might be incongruous understanding between items of the I-HFACS framework and construction safety accident reports. This may lead to different results from different analysts to the same accidents. Therefore, analysts need to be trained to ensure their results are consistent, which paves the way for the subsequent empirical study. The procedure of consistency check is shown in Figure 2.

The definition of subcategories of the initial version of the I-HFACS framework was drawn from the literature review. First, a random selection without repetition of 
TABLE 2: The category of statistical tests [41].

\begin{tabular}{|c|c|c|c|c|}
\hline \multirow[b]{2}{*}{ Goal } & \multicolumn{4}{|c|}{ Type of data } \\
\hline & $\begin{array}{l}\text { Measurement (from } \\
\text { Gaussian population) }\end{array}$ & $\begin{array}{l}\text { Rank, score, or measurement } \\
\text { (from non-Gaussian } \\
\text { population) }\end{array}$ & $\begin{array}{c}\text { Binomial (two } \\
\text { possible outcomes) }\end{array}$ & Survival time \\
\hline $\begin{array}{l}\text { Comparing three or more } \\
\text { unmatched groups }\end{array}$ & One-way ANOVA & Kruskal-Wallis test & Chi-square test & $\begin{array}{c}\text { Cox proportional hazards } \\
\text { regression }\end{array}$ \\
\hline $\begin{array}{l}\text { Comparing three or more } \\
\text { matched groups }\end{array}$ & $\begin{array}{c}\text { Repeated-measures } \\
\text { ANOVA }\end{array}$ & Friedman test & Cochran's $Q$ & $\begin{array}{l}\text { Conditional proportional } \\
\text { hazards regression }\end{array}$ \\
\hline $\begin{array}{l}\text { Testing association between } \\
\text { two variables }\end{array}$ & Pearson correlation & Spearman correlation & Chi-square test & \\
\hline $\begin{array}{l}\text { Predicting value from } \\
\text { another measured variable }\end{array}$ & Simple linear regression & & & $\begin{array}{c}\text { Predicting value from } \\
\text { another measured variable }\end{array}$ \\
\hline $\begin{array}{l}\text { Predicting value from several } \\
\text { measured or binomial } \\
\text { variables }\end{array}$ & $\begin{array}{l}\text { Multiple (non)linear } \\
\text { regression }\end{array}$ & & $\begin{array}{l}\text { Multiple logistic } \\
\text { regression }\end{array}$ & $\begin{array}{l}\text { Cox proportional hazards } \\
\text { regression }\end{array}$ \\
\hline
\end{tabular}

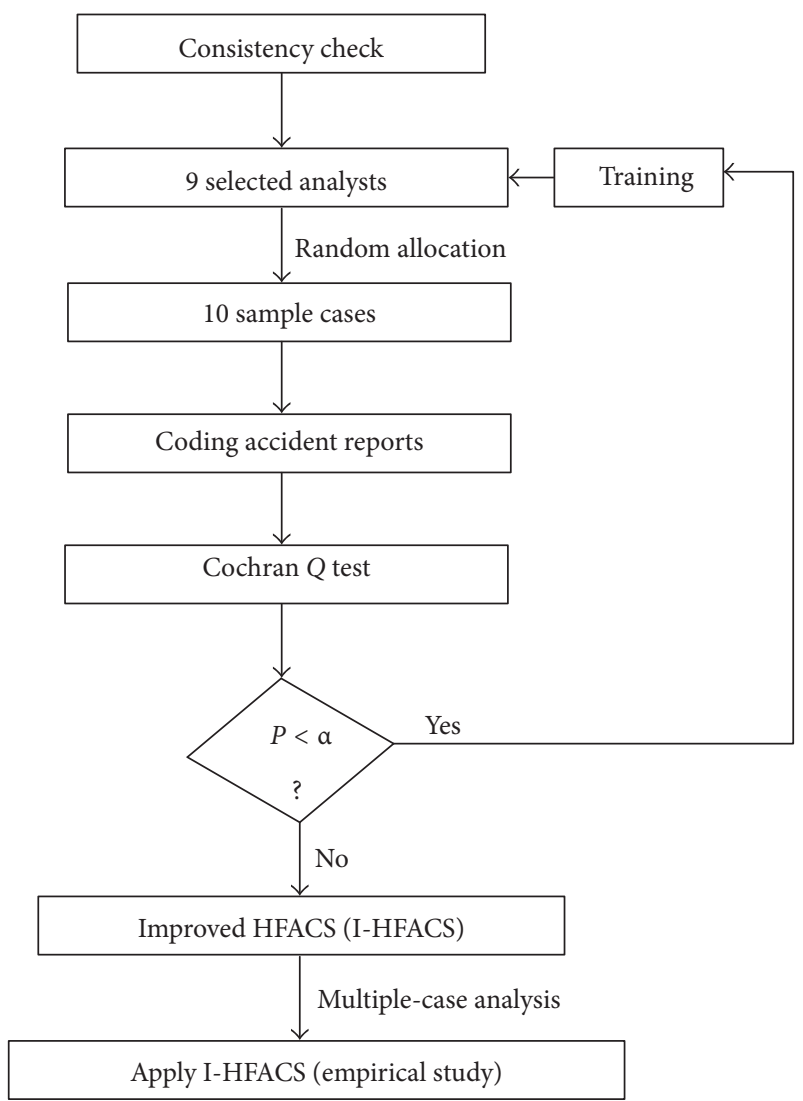

Figure 2: The procedure of consistency check.

10 Chinese construction safety accident reports from 150 sample cases (the selection of 150 sample cases is shown in Section 3.3.1) was regarded as research objects. The procedures to conduct random selection without repetition by Excel were described as follows: (1) code the 150 sample cases from 1 to 150 and suppose the group from which the selection has to be made is in A1:A150; (2) then, in the adjacent column, enter the formula $=\operatorname{RAND}()$; and $(3)$ in the next column over, enter the formula $=\operatorname{INDEX}(\$ A \$ 1: \$ A \$ 150$, RANK(B1, \$B\$1:\$B \$150)). Thus, a random selection without repetition of 10 cases was found. Second, 9 postgraduates were sent to obtain and analyze data. These 9 postgraduates have studied engineering management for 4 years in the stage of undergraduate and studied construction safety for 2 years in the stage of postgraduate. They have investigated construction sites and been trained together on how to use the framework. The training programs contained a detailed introduction, explanation, and description of the I-HFACS framework, each I-HFACS level, and individual I-HFACS subcategory. Each analyst independently worked on the 10 case accidents and worked on each accident report iteratively. For each analyst, if the cause of the sample case was related to some subcategory of the I-HFACS framework, the analyst coded "1." If not, the analyst coded " 0 ." Each I-HFACS subcategory was calculated a maximum of one time for each case. Thus, this count was simply conducted as an indicator of the existence or nonexistence of each subcategory within a given sample case. Finally, Cochran's $Q$ test was conducted to determine the improved HFACS framework (I-HFACS). In Cochran's Q test, if $P<\alpha$, it means that 9 analysts had not yet reached an agreement on the perception of each subcategory. As a result, 9 analysts should be retraining and the definition of each subcategory would be modified until $P>\alpha$. Ultimately, the improved HFACS framework (I-HFACS) was confirmed based on which multiple-case analysis was applied.

\subsection{Multiple-Case Analysis}

3.3.1. Sample Cases. The procedure of data collection is shown in Figure 3. Firstly, severe construction safety accidents between 2000 and 2016 were obtained from MOHURD, in a total of 430 cases. The severe construction safety accident was defined as the accidents of more than 3 and less than 10 deaths or more than 10 and less than 50 seriously injured people or direct economic losses being between 10 million and 50 million RMB (between 1.6 million and 8 million USD). However, 150 accident reports out of 430 were available in the public domain. For relatively small population (less than 1000), a larger sampling rate (about 30\%) is needed in the demand of higher accuracy [43]. The 150 cases were $34.9 \%$ of the 430 cases, meeting the sampling rate. Thus, 150 case 


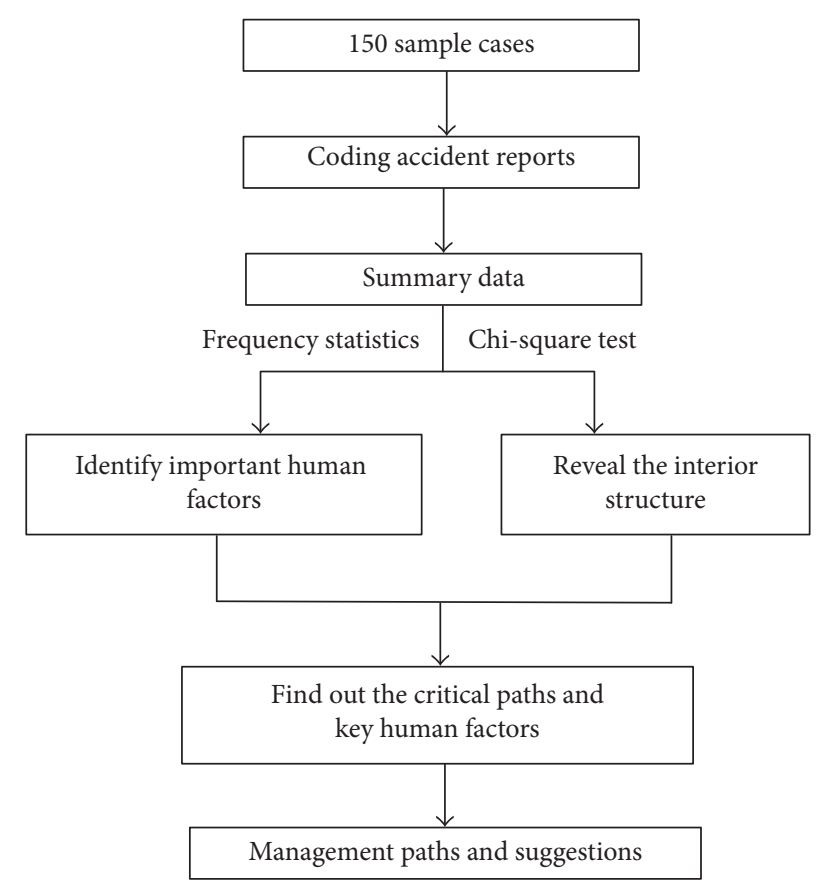

FIgURE 3: The procedure of data collection.

TABLe 3: The types of 150 construction safety accident cases.

\begin{tabular}{|c|c|c|c|c|c|c|c|c|c|c|}
\hline $\begin{array}{l}\text { Accident } \\
\text { type }\end{array}$ & $\begin{array}{l}\text { Object } \\
\text { strike }\end{array}$ & $\begin{array}{c}\text { Mechanical } \\
\text { damage }\end{array}$ & $\begin{array}{l}\text { Lifting } \\
\text { injury }\end{array}$ & $\begin{array}{c}\text { Electric } \\
\text { shock }\end{array}$ & Fire & $\begin{array}{l}\text { High-altitude } \\
\text { falling }\end{array}$ & Collapse & $\begin{array}{l}\text { Water } \\
\text { inrush }\end{array}$ & Explosion & Poisoning \\
\hline $\begin{array}{l}\text { Accident } \\
\text { number }\end{array}$ & 2 & 9 & 10 & 1 & 3 & 23 & 92 & 2 & 3 & 5 \\
\hline Rate & $1.33 \%$ & $6.00 \%$ & $6.67 \%$ & $0.67 \%$ & $2.00 \%$ & $15.33 \%$ & $61.33 \%$ & $1.33 \%$ & $2.00 \%$ & $3.33 \%$ \\
\hline
\end{tabular}

reports were taken as research objects. The types and number of 150 construction safety accident cases are presented in Table 3. Collapse and high-altitude falling were the main types of construction accidents. In particular, collapse accounted for $61.33 \%$ of the total number of severe accidents.

3.3.2. Data Analysis. Secondly, based on the I-HFACS framework, 9 analysts, who shared a common and identical understanding of the classification process and I-HFACS subcategories, coded these 150 sample cases. The principle of the coding was the same as in Section 3.2. Scores of 9 analysts were compiled. If each accident case scored more than 6 points in the same subcategory, which means $60 \%$ of the 9 analysts believed that the cause of the construction safety accident case was related to the subcategory of the I-HFACS framework for accident causes (more than $60 \%$ of the total is the majority or the greater part in Wikipedia), we code " 1 ," otherwise " 0 ."

Then, the data collected from the 150 cases were counted. Subsequently, frequency analysis was conducted to identify the relatively important human factors. The chi-square test was undertaken to highlight the associations between the subcategories at the adjacent levels and the same levels in the I-HFACS analytical framework. Lastly, based on the important human factors identified in frequency analysis and the associations between subcategories, the critical paths and key human factors were consequently identified.

\section{Development of the Improved HFACS (I-HFACS)}

4.1. One Level Added and Some Subcategories Adjusted. The initial HFACS framework was modified according to specific characteristics of the construction industry, for example, the added level and the adjustment and modification of categories and subcategories (Figure 4). The changes from the original model are shown in grey boxes.

The fifth- (or the top-) level "external factors" were added, which meant to capture the impact of safety deficiencies outside the scope of organizations. Meanwhile, "external factors" include "regulatory factors" and "economic/political/social/legal environment." Reinach and Viale noted that the regulatory environment contributed to an accident, even though indirectly [44]. The inadequacy of the regulatory environment may lay a breeding ground for inertia and fluke mind of main bodies in construction [45]. Besides, Khosravi et al. identified the role of the economic/political/social/legal environment in unsafe acts [29]. The response of the client under these factors will present a few constraints, in which parties involved in the project have the potential to act unsafely. The process of cause and effect tends to restrain front-line operators through inapposite construction plans and control programs, resulting in improper preconditions and actions [25]. 


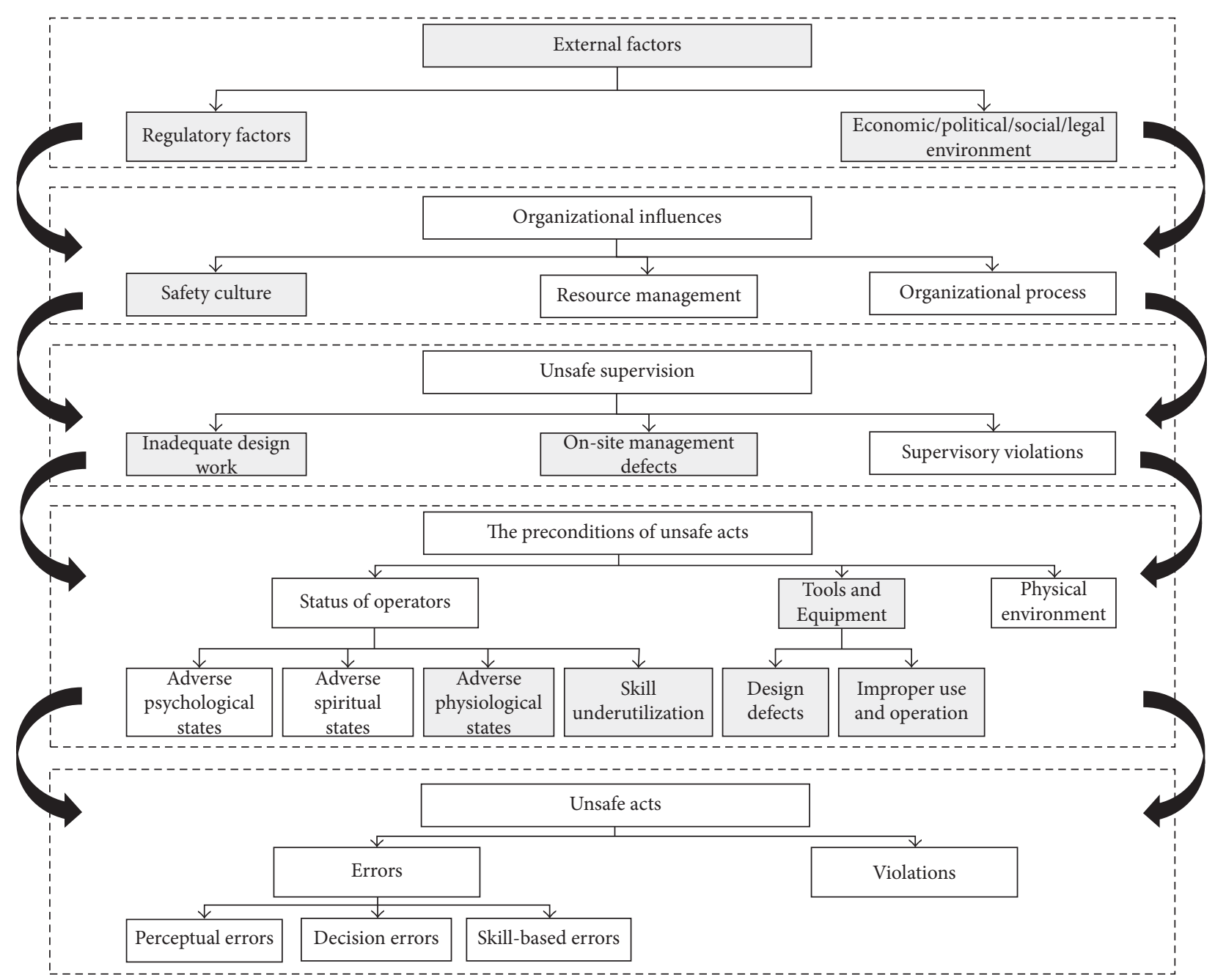

FIGURE 4: The initial HFACS framework in the construction industry.

"Organizational climate" was replaced with "safety culture" in level 4. In fact, there has always been confusion between safety culture and safety climate [46]. Teo and Feng argued that safety climate was not an alternative to safety culture [47]. Safety climate is the outward appearance of safety culture and a time-dependent phenomenon, prone to change and relatively unstable $[48,49]$. Safety culture is the outcome of group and individual perceptions, values, competencies, and behavior patterns. The characteristics of organizations with a positive culture are communicating based on mutual trust, through identical recognitions of the significance of safety and conviction in the effectiveness of precautions [50]. Therefore, "organizational climate" was replaced by "safety culture."

In the third level of HFACS, there were 2 changes: (1) merging the three subcategories ("inadequate supervision," "planned inappropriate operations," and "failure to correct a known problem") of the traditional HFACS into "on-site management defects." Shohe and Laufer suggested supervisors were the role players who help with the organization and promotion of daily construction management [51]. Kim et al. indicated that site supervision, plan management, and correcting a known problem were three important functions of on-site management [52]. Thus, we merged the three subcategories into "on-site management defects"; and (2) adding a subcategory "inadequate design work" to this level. Many researchers summarized management performance of project managers into system design and supervisory control [53]. Having the proper planning in conjunction with security management in the construction prophase can greatly reduce the occurrence of accidents [54, 55]. Qingren et al. pointed out that design work of project managers was to provide guidance for construction workers by making a variety of specifications, procedures, schemes, and plans [56]. Therefore, this subcategory (i.e., "inadequate design work") was added in this study.

The second level of the traditional HFACS included "environmental factors" (physical environment and technological environment), "condition of individuals" (adverse mental states, adverse physiological states, and physical/mental limitations), and "personal factors" (crew resource mismanagement and personal readiness). According to the characteristics of the construction industry, it is well recognized that unsafe acts of operators should be examined from the perspective of "man-machine environment" $[57,58]$. The specific changes of the subcategories included 
TABle 4: Cochran's $Q$ test about the identical effects by the 9 analysts.

\begin{tabular}{lcccccccccc}
\hline Accident code & 1 & 2 & 3 & 4 & 5 & 6 & 7 & 8 & 9 & 10 \\
\hline$P$ value & 0.059 & 0.056 & 0.113 & 0.064 & 0.080 & 0.082 & 0.077 & 0.053 & 0.064 & 0.067 \\
\hline
\end{tabular}

the following: (1) "condition of individuals" and "personal factors" were merged into "status of operators." "Status of operators" involved "adverse spiritual states," "adverse psychological states," "adverse physiological states," and "skill underutilization." In the construction industry, apart from psychological and physiological states $[59,60]$, skill underutilization was also found to cause accidents [61]. Many researchers maintained that spiritual states and psychological states were the same thing. However, according to the confusion in psychology (the word "psychology" that originates from psyche is regarded as "spirit") and based on the localization research orientation (the psychology belongs to the inner world of one's mind, while the spirit is the outer one), this study considered that "psychology" equating to "spirit" was unsuitable in psychology [62] and "status of operators" should involve "adverse spiritual states" and "adverse psychological states"; (2) "tools and equipment" involved "design defects" and "improper use and operation." Numerous studies reported that man-machine ergonomics was overlooked in the design of mechanical equipment and safety warning signs, which did not match with behavior rules of workers' sense of touch, attention, and reaction speed [58, 63]. In addition, Choudhry and Dongping found that workers may go against operating instructions because of time and labor savings [64]. Therefore, "tools and equipment" included "design defects" and "improper use and operation"; and (3) "environmental factors" in the traditional HFACS included the technological and physical environment. However, in the construction industry, "environmental factors" refer more to the physical environment of the construction site. Similarly, the technological environment emphasizes on the quality of inspection and maintenance and equipment operability which were involved in "tools and equipment." Thus, environmental factors of the traditional HFACS were changed into "physical environment."

4.2. The Definition of Each Subcategory. Having developed the initial HFACS framework in the construction industry, the improved HFACS in construction (I-HFACS) based on the initial HFACS framework was needed to be established. Through a critical review of literature [18,38,64-67], this study identified the initial version of the I-HFACS framework according to the following 3 principles: (1) all detailed items reflect the subcategory they belong to; (2) there is a distinct division among different detailed items; and (3) all detailed items are clear and not ambiguous. Then, the consistency check was carried out to confirm the final improved HFACS framework (I-HFACS). Cochran's $Q$ test was undertaken in this step to assess whether different observers in the same phenomenon had consistent results amongst themselves (i.e., interobserver variability). For the significant level $\alpha$, if $P$ value is more than $\alpha$, there are identical effects among the 9 analysts. If $P$ value is less than $\alpha$, there are not [68]. Cochran's $Q$ test was run in SPSS 19.0. We defined $\alpha=0.05$; the analytic results based on the initial version of the I-HFACS framework showed " $P$ value $=0.02<\alpha=0.05$." Based on analytic results, the initial version of the I-HFACS framework was adjusted and 9 analysts should be retraining. Then, 9 analysts performed a second round of accident analysis. After 3 rounds of iterations, the analytic results showed " $P=0.059>\alpha=0.05$," which came to an agreement on the perception of each subcategory. Finally, based on the ultimate version, 9 analysts analyzed the 10 construction safety cases. The results are shown in Table 4. It demonstrated that all analysts had identical effects, indicating the ultimate version of the I-HFACS framework was the effective basis for analysis of construction safety accidents. The final version of the I-HFACS framework is shown in Table 5.

4.3. The Interior Structure. The chi-square test was conducted to estimate the statistical strength of associations between subcategories at the adjacent levels and the same levels of I-HFACS. In chi-square $(\chi 2)$ analysis, if $P$ value is small $(P<0.05)$, the null hypothesis $\left(H_{0}\right)$ will be rejected and the alternative hypothesis $\left(H_{\mathrm{a}}\right)$ should be accepted. This indicates there are significant associations, and vice versa. Meanwhile, effective chi-square $(\chi 2)$ analysis requires less than or equal to 25 percent of theoretical frequency that has expected count less than 5, or significant Fisher's exact tests if more than 25 percent of it. Based on the theoretical assumptions of the HFACS framework, subcategories at downward levels are dependent on subcategories at upper levels and cannot adversely influence upper subcategories [69]. Higher levels in the I-HFACS are deemed to cause changes at the lower levels, thus going beyond what may be deemed a simple test of co-occurrence between subcategories [70]. Then, odds ratio (OR) was used to estimate the probability of the existence of one I-HFACS subcategory associated with another subcategory concomitantly existing. In OR analysis, when the OR value is greater than 1 , it can be seen that downward-level subcategories are more likely to occur when upper-level subcategories are in place. In a more technical language, the OR value is a measure of effect size, describing the strength of associations or nonindependence between two binary data values [71]. In this study, chi-square $(\chi 2)$ analysis was carried out using SPSS 19.0. We selected the associations in the condition of $P<0.05$ and $\mathrm{OR}>1$. These significant associations are summarized in Tables 6 and 7.

As for the analysis of upper-level and adjacent downward-level subcategories in the I-HFACS framework, analysis of the strength of associations at the "external factors" level and "organizational influences" level showed 3 pairs of significant associations $(P<0.005)$. In particular, "safety culture" was over 17 times more likely to occur when 
TABLE 5: The I-HFACS framework.

Regulatory factors

Level 5: external factors

Economic/political/social/legal environment
Level 4: organizational influences

Organizational process
A: regulator cannot "reach" duty holders; B: ineffective regulators' inspections and enforcement; C: inadequate regulatory standards A: insufficient laws, regulations, and policies related to construction safety; B: insufficient publicity of laws, regulations, and policies related to construction safety; C: society prioritizing other issues over safety; E: supply problems: services/materials/labor; F: restrictive economic conditions

A: managers' lack of values and beliefs of safety; B: ineffective enterprise safety system; C: not well-organized enterprise safety organization or ambiguous responsibilities (from the corporate level)

A: inefficient human resources allocation and selection (from the enterprise level); B: insufficient safety training program; C: lack of safety investment and overcutting costs; D: purchase of unsuitable materials (type or size) and equipment

A: ineffective procedures and contingency plan; B: excessive emphasis on other purposes rather than safety management; C: failed to fulfill the designated enterprise safety system and responsibilities; D: ineffective resource supervision and fulfillment

A: ineffective supervisory system, safety plans, and schemes on site; B: excessive task load; C: ineffective personnel allocation and labor organization on site

A: failed to fulfill the designed work on site and responsibilities; B: failure to correct unsafe acts timely; C: ineffective potential safety hazard checking and controlling; D: ineffective track management

A: failed to comply with company safety rules and regulations; $\mathrm{B}$ : violation in commanding; $\mathrm{C}$ : authorized unqualified working team or group to perform

A: stress; B: abnormal feeling fluctuation; C: fluke mind, empiric mind, impulse mind, and others

A: physical fatigue; B: illness; C: poisoning; D:

physical limitations
A: distractions; B: weak safety consciousness; C:

Status of operators states

Adverse spiritual states

Skill underutilization

Design defects

acts

Tools and

equipment

Improper use and operation poor safety attitude; $\mathrm{D}$ : excessive self-confidence A: inadequate experience; B: inadequate safety knowledge and skills

A: lack of inconspicuous warnings and signals; B: lack of the consideration of man-machine ergonomics

A: use of tools and equipment against operating specification; B: use of tools/equipment with defects; C: overload use of tools and equipment;

D: not using PPE (personal protective equipment)

A: dirty, chaotic, and poor work environment; B: noise/lighting/ground conditions; C: narrow space; D: insufficient ventilation and oxygen; E: poor geological environment; F: bad weather 
TABLE 5: Continued.

\begin{tabular}{lll}
\hline & Perceptual errors & $\begin{array}{c}\text { A: wrong perception of equipment, } \\
\text { environment, and personnel; B: } \\
\text { misunderstanding of SOP (standard operating } \\
\text { procedure) }\end{array}$ \\
Level 1: unsafe acts & $\begin{array}{c}\text { Errors } \\
\text { Decision errors }\end{array}$ & $\begin{array}{c}\text { A: poor risk identification; B: exceeded ability; C: } \\
\text { poor decision }\end{array}$ \\
& Skill-based errors & $\begin{array}{c}\text { A: selecting the wrong method to perform; B: } \\
\text { omitted step in the procedure; C: simplified } \\
\text { operation procedure } \\
\text { A: routine violations; B: exceptional violations }\end{array}$ \\
\hline
\end{tabular}

there were "external factors" issues associated with "regulatory factors." At I-HFACS level 4 and level 3, there were also 3 pairs of significant associations. Of these comparisons, over 6 times more likely, "on-site management defects" occurred in the presence of "organizational process" at the organizational level. Level 3 "unsafe supervision" and the adjacent downward-level "preconditions for unsafe acts" suggested 4 pairs of relationships. As for the OR value, "skill underutilization" was around 4 times more likely to happen in the existence of "supervisory violations." There were 6 pairs of evident relationships between level 2 and level 1 . Particularly, inspection of the associated odds ratios showed more than 4.5 times increase in the likelihood of "skill-based errors" in the presence of "skill underutilization," and "perceptual errors" were around 4 times more likely to emerge when "poor physical environment" existed.

As for the analysis of the same-level subcategories in the I-HFACS framework, there were 6 pairs of significant associations existing. Of these comparisons, the OR values of "regulatory factors $\times$ economic/political/social/legal environment," "adverse physiological states $\times$ physical environment," and "adverse spiritual states $\times$ skill underutilization" were relatively high, describing the relative high strength of associations.

\section{Understanding the Human Factors by Applying I-HFACS}

5.1. The Identification of Important Human Factors. In statistics, the absolute frequency of each I-HFACS subcategory was the number of times the I-HFACS subcategory occurs in the 150 sample cases. There were a total of 1308 instances of failures indicating the contributing factors in 150 sample cases by the use of the I-HFACS framework. Statistical analysis results showed that 294 instances of errors, 22.5 percent of all, were found at the "unsafe acts" level. Failures at this level were implicated in $96.7 \%$ (145) of accidents. The most frequent subcategories at the "unsafe acts" level were skill-based errors (64\%) and violations (78.7\%). There were $344(26.2 \%)$ instances of failures in total, with $91.3 \%$ (137) of all accidents analyzed at the "preconditions for unsafe acts" level. The preconditions most commonly entailed were "adverse spiritual states" (67.3\%), followed by "skill underutilization" (51.3\%). At level 3 "unsafe supervision," there were $323(24.7 \%)$ instances of failures, involved in $100 \%$ (150) of sample cases. All factors at level 3 were very generally existing, with “on-site management defects" (94.7\%), "supervisory violations" (65.3\%), and "inadequate design work" (55.3\%). At the "organizational influences" level, 239 $(18.3 \%)$ instances of failures were on the record, involved in $87.3 \%$ (131) of sample cases. The most frequent factors of level 4 were "organizational process" (65.3\%) and "safety culture" (56\%). In the data set, failures at the "external factors" level were 108 (8.3\%) instances, with "regulatory factors" (64\%) being the most common factor in level 5, implicated in $64.7 \%$ (97) of all accidents analyzed.

The results in Figure 5 indicated that firstly the addition of added level 5 in this study, external factors, was of significance. Meanwhile, all levels made a great difference to construction accidents, and human factors in a low level accounted more for contribution of accidents, especially level 3 unsafe supervision. Then, this study defined the relatively important subcategories using the Pareto principle. The 11 important factors reflecting significant information are demonstrated in Figure 6. A total of 1042 frequencies were around 80 percent of the whole 1308 instances of human errors according to the Pareto principle. These important human factors were "regulatory factors" in level 5, "safety culture" and "organizational process" in level 4, "inadequate design work," "on-site management defects," and "supervisory violations" in level 3, "adverse spiritual states," "skill underutilization," and "improper use and operation" in level 2, and "skill-based errors" and "violations" in level 1.

Note that I-HFACS levels may add up to more than $100 \%$ as more than one subcategory at a given level can be identified for each case.

5.2. The Critical Paths and Key Human Factors. Based on the 11 important human factors identified in frequency analysis and the associations between subcategories, we could further identify the critical paths and key human factors. Unsafe acts (human errors) are the direct factors and responsible for over 80 percent of accidents, of which "skill-based errors" and "violations" are the key factors in level 1 [4]. For the reason that latent factors are hard to be associated with an accident or explicitly examined [36], we can track key latent factors on the basis of the key human errors that have been identified [69]. Then, "adverse spiritual states" and "skill underutilization" were defined as the key human factors in level 2, which associated with the key factors in level 1. In level 3, although "inadequate design work" had the association with "supervisory violations," the OR value of which indicated a relatively low effect size. And "supervisory 
TABLE 6: Significant chi-square test of associations and associated values of OR for the analysis of upper-level and adjacent downward-level subcategories in the I-HFACS framework $(P<0.05$; OR $>1)$.

\begin{tabular}{|c|c|c|c|c|}
\hline $\begin{array}{l}\text { Significant association between upper-level and } \\
\text { adjacent downward-level subcategories in the } \\
\text { I-HFACS framework }\end{array}$ & $\chi^{2}$ value & $P$ value & $\begin{array}{l}\chi^{2} \text { test } \\
\text { Theoretical frequency (expected count }<5)\end{array}$ & OR value \\
\hline \multicolumn{5}{|c|}{ I-HFACS level 5 association with level 4 subcategories } \\
\hline Regulatory factors $\times$ safety culture & 52.978 & 0.001 & 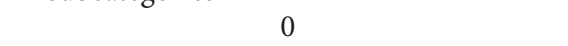 & 17.857 \\
\hline Regulatory factors $\times$ organizational process & 6.771 & 0.009 & 0 & 2.500 \\
\hline $\begin{array}{l}\text { Economic/political/social/legal } \\
\text { environment } \times \text { resource management }\end{array}$ & 4.550 & 0.033 & $25 \%$ & 3.633 \\
\hline \multicolumn{5}{|c|}{ I-HFACS level 4 association with level 3 subcategories } \\
\hline Safety culture $\times$ inadequate design work & 6.191 & 0.013 & 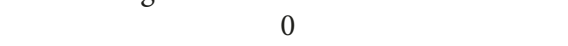 & 2.297 \\
\hline $\begin{array}{l}\text { Organizational process } \times \text { on-site management } \\
\text { defects }\end{array}$ & 6.070 & 0.014 & $25 \%$ & 6.261 \\
\hline Organizational process $\times$ supervisory violations & 4.637 & 0.031 & 0 & 2.143 \\
\hline \multicolumn{5}{|c|}{ I-HFACS level 3 association with level 2 subcategories } \\
\hline $\begin{array}{l}\text { Inadequate design work } \times \text { adverse psychological } \\
\text { states }\end{array}$ & 6.635 & 0.010 & -5 & 2.940 \\
\hline $\begin{array}{l}\text { Inadequate design work } \times \text { adverse physiological } \\
\text { states }\end{array}$ & 4.867 & 0.027 & 0 & 3.962 \\
\hline Supervisory violations $\times$ adverse spiritual states & 4.839 & 0.028 & 0 & 2.196 \\
\hline Supervisory violations $\times$ skill underutilization & 8.904 & 0.003 & 0 & 2.858 \\
\hline \multicolumn{5}{|c|}{ I-HFACS level 2 association with level 1 subcategories } \\
\hline Adverse spiritual states $\times$ decision errors & 4.919 & 0.027 & 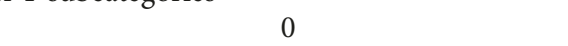 & 2.601 \\
\hline Adverse spiritual states $\times$ skill-based errors & 12.507 & 0.001 & 0 & 3.603 \\
\hline Adverse spiritual states $\times$ violations & 7.740 & 0.005 & 0 & 3.046 \\
\hline Skill underutilization $\times$ decision errors & 17.324 & 0.001 & 0 & 5.333 \\
\hline Skill underutilization $\times$ skill-based errors & 19.391 & 0.001 & 0 & 4.509 \\
\hline Poor physical environment $\times$ perceptual errors & 7.844 & 0.005 & 0 & 2.819 \\
\hline
\end{tabular}

All tests have 1 degree of freedom. All other comparisons were nonsignificant.

violations" in level 3 had effects on both the two key factors in level 2. Similarly, tracking to the upper level according to the key factors in the adjacent downward level, "supervisory violations" in level 3, "organizational process" in level 4, and "regulatory factors" in level 5 were identified the key factors. Thus, the critical path was the overall link, as seen in Figure 7, which responded positively to Reason's hypothesis and indicated actions could be taken from these "upstream and latent" factors of the system to reduce and prevent unsafe acts. The original decisions and acts at the highest levels in regulation originally had effects on "organizational processes" in level 4. Poor "organizational processes" were associated with "supervisory violations" at the level of "unsafe supervision," which showed significant statistical associations with "adverse spiritual states" and "skill underutilization" in level 2, and hence indirectly were ultimately at the root of "skill-based errors" and "violations" resulting in accidents.

\section{Discussion}

This study explored the application of an improved HFACS (I-HFACS) to guide accident analysis and make a better understanding of the safety implications of human errors in construction. This model enabled to accommodate not only the low level of unsafe acts (active failures) but also higher levels-the preconditions, supervision, organizational influence, and external factors (latent failures). Specifically, all subcategories within the I-HFACS framework were observed in accident cases, which indicated its ability to capture contributing factors and suggested HFACS was applicable for construction accidents if being modified and improved. Secondly, it can be observed that the added fifth (or the top) level called "external factors" was identified in accident reports, and "external factors" had influence on unsafe acts from a practical aspect. This finding suggested that it was necessary and practical to add such a highest level in the I-HFACS framework. Thirdly, the vast majority of I-HFACS subcategories had a relatively common occurrence in Figure 6, and only 2 subcategories had low frequencies of occurrence (below 10\%). It can be interpreted the low numbers may report either the sensitivity of issues ("inadequate design work") or handling with a less tangible issue ("economic/ political/social/legal environment"). These findings showed a strong evidence for the system approach and Reason's model of human factors.

This study also made a contribution to providing quantification evidence to reveal an analytical I-HFACS mechanism to interpret how activities and decisions made by the upper management led to operator errors and subsequent accidents. Such a mechanism also helped to identify the critical paths and key factors, illuminating the redesign of safety guidelines in the construction industry and helping construction managers with better decision-making.

"Regulatory factors" were of great importance in level 5. Feng found out that if a firm had satisfied the minimal safety 
TABLE 7: Significant chi-square test of associations and associated values of OR for the analysis of the same-level subcategories in the I-HFACS framework $(P<0.05 ;$ OR $>1)$.

\begin{tabular}{|c|c|c|c|c|c|}
\hline $\begin{array}{l}\text { Significant association between the same-level } \\
\text { subcategories in the I-HFACS framework }\end{array}$ & $\chi^{2}$ value & $\begin{array}{c}P \\
\text { value }\end{array}$ & $\begin{array}{l}\chi^{2} \text { test } \\
\text { Theoretical frequency }(\text { expected } \\
\text { count }<5)\end{array}$ & $\begin{array}{c}\text { Fisher's exact } \\
\text { test } \\
P \text { value }\end{array}$ & $\begin{array}{c}\text { OR } \\
\text { value }\end{array}$ \\
\hline \multicolumn{6}{|c|}{ I-HFACS level 5 subcategories } \\
\hline $\begin{array}{l}\text { Regulatory } \\
\text { factors } \times \text { economic/political/social/legal } \\
\text { environment }\end{array}$ & 4.333 & 0.037 & $25 \%$ & - & 6.859 \\
\hline \multicolumn{6}{|c|}{ I-HFACS level 4 subcategories } \\
\hline Safety culture $\times$ resource management & 6.191 & 0.039 & 0 & - & 2.043 \\
\hline \multicolumn{6}{|c|}{ I-HFACS level 3 subcategories } \\
\hline $\begin{array}{l}\text { Inadequate design work } \times \text { on-site management } \\
\text { defects }\end{array}$ & 6.635 & 0.010 & $50 \%$ & 0.009 & 1.107 \\
\hline Inadequate design work $\times$ supervisory violations & 3.97 & 0.046 & 0 & - & 1.991 \\
\hline \multicolumn{6}{|c|}{ I-HFACS level 2 subcategories } \\
\hline $\begin{array}{l}\text { Adverse physiological states } \times \text { physical } \\
\text { environment }\end{array}$ & 4.919 & 0.006 & $25 \%$ & - & 4.098 \\
\hline Adverse spiritual states $\times$ skill underutilization & 15.092 & 0.001 & 0 & - & 4.145 \\
\hline
\end{tabular}

All tests have 1 degree of freedom. All other comparisons were nonsignificant.

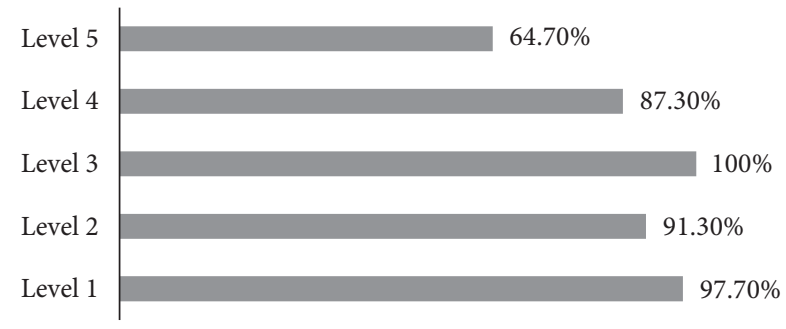

Figure 5: The total frequency comparison of each level.

requirement set by government regulations, increased investments in the more cost-effective elements (e.g., accident investigations and safety inspections) would yield much greater benefits [72]. Recurrent issues emerged from the data involved poor performance and enforcement of administrative duties. "Regulatory factors" showed a high relationship with "safety culture" in this study. Previous studies have reported that incomplete regulatory standards and poor enforcement were critical factors for determining safety culture and practices of organizations in the construction industry $[38,73]$. Findings in this study demonstrated "regulatory factors" had the potential to create the conditions where organizations are able to establish effective structures. "Regulatory factors" could provide the reference guidelines for policies, norms, and culture to make organizations' safe performance and accident prevention possible $[74,75]$. Therefore, enhancing the governments' regulation and making regulators' inspections and enforcement effective are required.

"Organizational process" was a key factor in level 4. It can be observed that "regulatory factors" were associated with inadequacies in the "organizational process." Poor "organizational processes" were associated with "supervisory violations" at the level of "unsafe supervision," which showed significant statistical associations with "adverse spiritual states" and "skill underutilization" in level 2, and at the end of several errors (i.e., "skill-based errors" and "violations") in operation of workers contributing to accidents, albeit indirectly. This overall link was the critical path in this study, and this finding responded positively to Reason's hypothesis; that is, failures in upper-level management had a negative impact on supervision, which successively affected preconditions and follow-up operations. For the "organizational process" subcategory, from the data of accident reports, ineffective procedures and contingency plan and excessive emphasis on other purposes rather than safety management were common failures. Previous studies also highlighted the importance of the "organizational process" affecting supervision [34]. Li and Harris argued welldeveloped organizational processes were essential to safety management systems [39], and safety commitment in the supervisory level was supposed to be right from the organization of upper levels [21]. Therefore, findings of this study suggested that assessment and renovation of procedures should be made and implemented for safety management.

"Supervisory violations" were a key factor at the supervision level. According to the collected data, frequent violating behaviors of supervisors in construction projects included authorizing processes that were not up to the standard, failing to enforce rules and regulations, authorizing workers to undertake dangerous construction works, and conducting supervision without qualifications. The front-line supervision will affect their workers' attitude and behavior towards safety [76]. In this study, "supervisory violations" had the associations with "adverse spiritual states" and "skill underutilization." The paths of significant associations revealed this connection. "Supervisory violations" may affect the way individuals and team members handle in the workplace, together with their ability to make decisions based on the risk perception profile of both the 


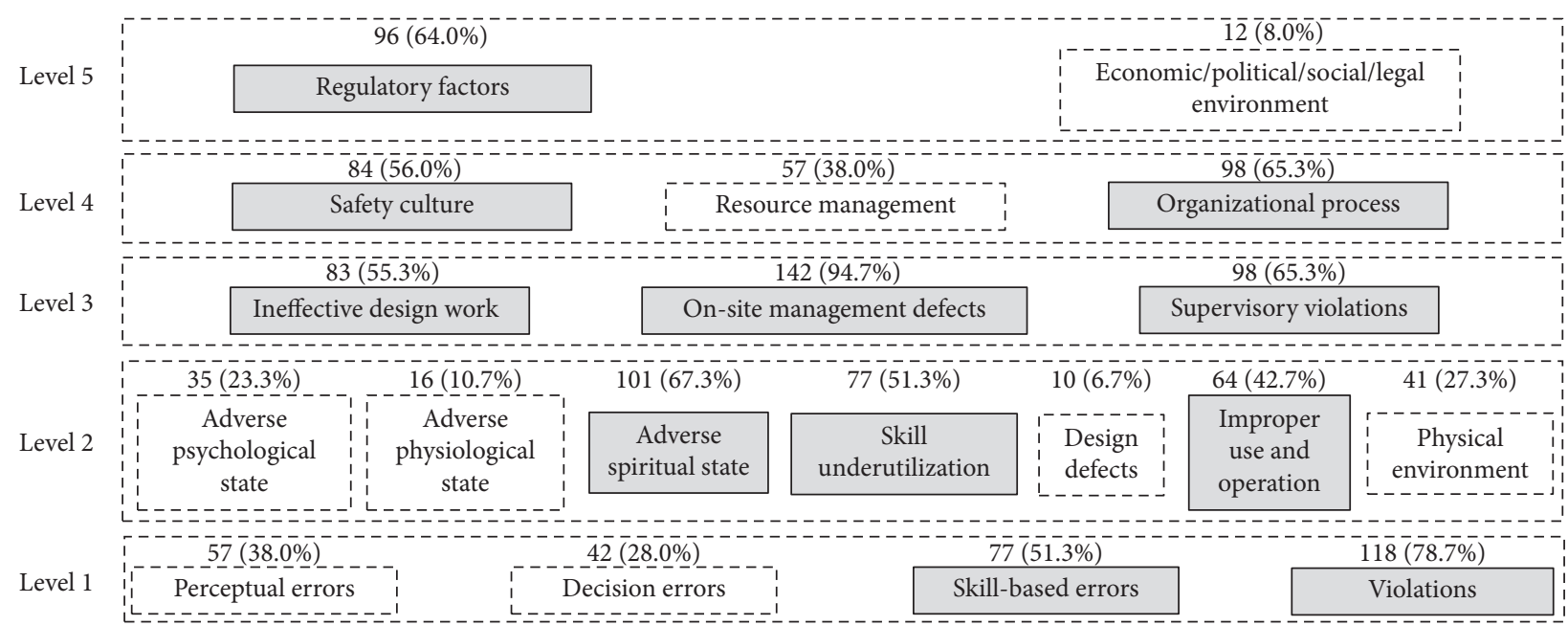

FIGURE 6: The relatively important factors of each level.

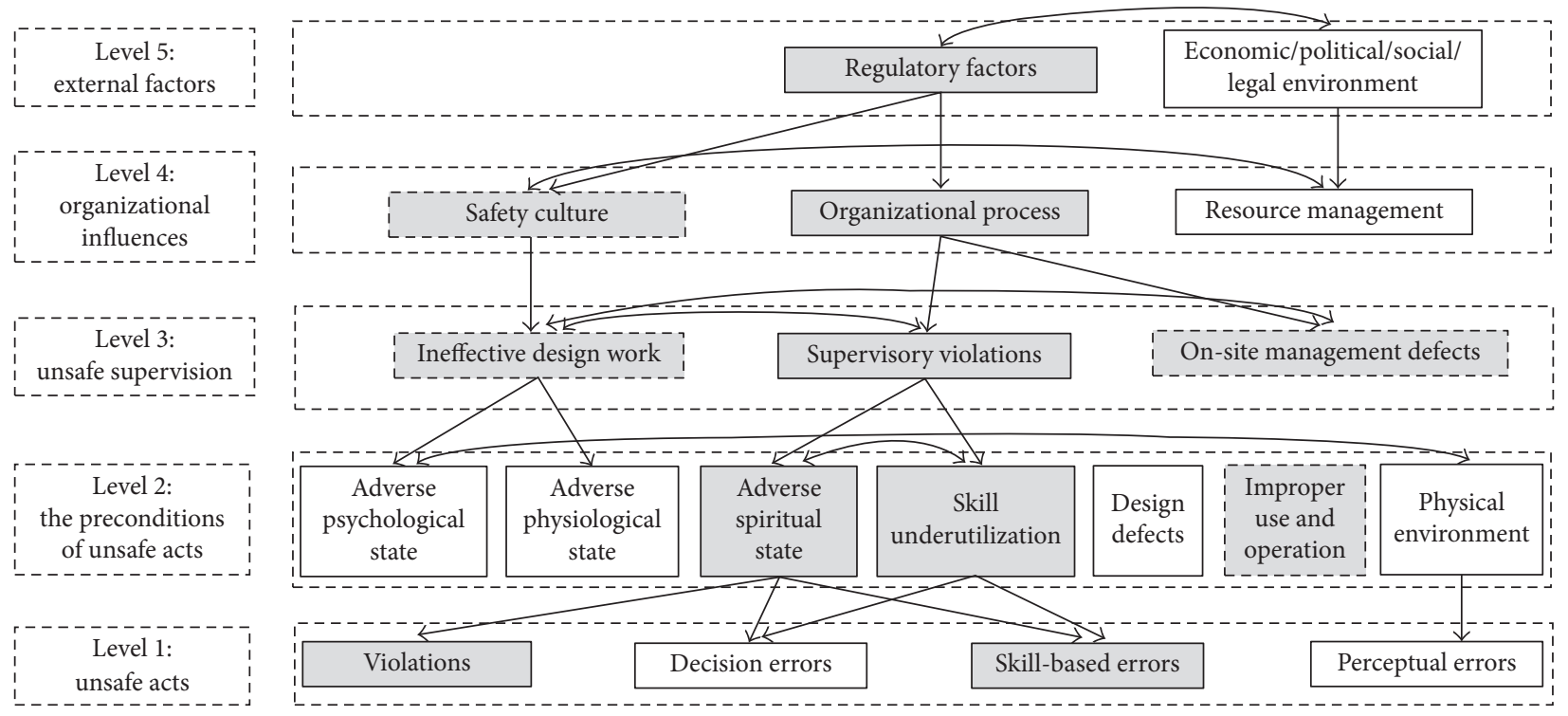

FIgURE 7: Critical paths and key human factors in the I-HFACS framework.

supervisor and the entire team. Li and Harris also observed that supervision was the key area and link between the upper management of the organization level and the downward precondition level [39]. Guidelines for enhancing supervision suggested ensuring the appropriate individuals were selected for supervisory roles, providing appropriate training based on the competencies required, and the continual monitoring and assessment of the supervisory system in place appear to be particularly pertinent in this case $[77,78]$.

The key factors of level 2 were "adverse spiritual states" and "skill underutilization," and the issues of "skill-based errors" and "violations" were essential at level 1. Systems theory advocated that exclusions of "upstream and latent" failures were advisable for dealing with operators' unsafe acts. Several significant relationships existed between psychological issues and errors and violations committed by construction workers. This, to some extent, supported Reason's assertion of a "many-to-one" mapping of psychological conditions and operations [21, 69]. Wenner and Drury also believed violations and errors could be removed by ensuring a favorable physical environment of the preconditions as well [79]. Furthermore, the associations between "adverse spiritual states," "skill underutilization," and "supervisory violations" interpreted that "skill-based errors" and "violations" (the key factors at level 1) could be addressed by tracing the upper level of supervision. Recurrent issues in cases involve distractions, weak safety consciousness, poor safety attitude, and excessive selfconfidence in the "adverse spiritual state" subcategory and inadequate experience and inadequate safety knowledge and skills in the "skill underutilization" subcategory. Moreover, Reason asserted that, in most accident databases, violations were far more common than errors, as shown in Figure 6 [69]. Violations were categorized into unintentional and deliberate violations. Results of this study showed that unintentional violations were able to be addressed by 
enhancing awareness though supervision and training programs. Similarly, deliberate violations have become an acceptable part of the program and even managers often took the attitude of tolerance [79]. This suggested the most efficient way to solve the issues of deliberate violations was guaranteeing the representing procedures, such as program evaluation and redevelopment of supervision and organization levels, as found in this study.

\section{Conclusions}

This study enriched the application of HFACS for examining construction accidents. An analytical I-HFACS mechanism was proposed to gain a better understanding of how activities made by upper management lead to operator errors. This study highlighted the critical paths, which were the overall link. The original decisions and acts at the highest levels in regulation originally had effects on "organizational processes" in level 4. Poor "organizational processes" were associated with "supervisory violations" at the level of "unsafe supervision," which showed significant statistical associations with "adverse spiritual states" and "skill underutilization" in level 2, and hence indirectly were ultimately at the root of "skill-based errors" and "violations" resulting in accidents. The result showed clearly defined statistically described paths that related errors with inadequacies at both the immediately adjacent and also higher levels in the organization and regulation. To reduce significantly the accident rate, these "paths to failure" relating to these organizational and human factors must be addressed. This suggested that only by understanding the context that induced unsafe acts could prevent the occurrence of accidents, and it would be more efficient if actions could be taken from these "upstream and latent" factors of the system.

And this study also identified the 7 key factors, "regulatory factors," "organizational process," "supervisory violations," "adverse spiritual state," "skill underutilization," "skill-based errors," and "violations," which suggested that, under the circumstances of limited resources, it would be more effective to focus on the critical paths and key factors for the improvement of construction safety performance. This study satisfied the need to redesign safety guidelines in the construction industry and helped construction managers with better decision-making. Further work can be undertaken to establish if a similar pattern of results is found in other countries and cultures.

\section{Data Availability}

The data used to support the findings of this study are from the Ministry of Housing and Urban-Rural Development of the People's Republic of China (MOHURD).

\section{Conflicts of Interest}

The authors declare that the funding programmes do not lead to any conflicts of interest regarding the publication of the paper.

\section{Acknowledgments}

The authors gratefully acknowledge the financial support of the National Natural Science Foundation of China (Grant no. 71471023) and Fundamental Research Funds for the Central Universities (Grant nos. 106112016CDJSK03XK07 and 2017CDJSK03PT03).

\section{References}

[1] US Bureau of Labor Statistics, Health and Safety Executive. National Census of Fatal Occupational Injuries in 2016, 2016, https://www.bls.gov/news.release/archives/osh_11092017.pdf.

[2] Health and Safety Executive, Health and Safety in Construction in Great Britain, 2015, http://www.hse.gov.uk/ statistics/industry/construction/construction.pdf.

[3] G. Ofori, "Challenges of the construction industries in developing countries: lessons from various countries," in Proceedings of 2 nd International Conference of the UB TG29 On Construction In Developing Countries Challenges facing The Construction Industry in Developing Countries, pp. 15-17, Gaborone, Botswana, November 2000.

[4] Health and Safety Executive, Strategies to Promote Safe Behavior as Part of a Health and Safety Management System, ISBN 0-7176-2352-1, HSE Books, Sudbury, Sussex, UK, ISBN 0-7176-2352-1, 2002.

[5] M. Döös, T. Backström, and C. Sundström-Frisk, "Human actions and errors in risk handling - an empirically grounded discussion of cognitive action-regulation levels," Safety Science, vol. 42, no. 3, pp. 185-204, 2004.

[6] R. M. Choudhry, "Implementation of BBS and the impact of site-level commitment," Journal of Professional Issues in Engineering Education and Practice, vol. 138, no. 4, pp. 296304, 2012.

[7] I. S. M. Kamal, I. N. Ahmad, and M. I. N. Ma'arof, "Review on accidents related to human factors at construction site," Current Trends in Ergonomics, vol. 10, pp. 154-159, 2013.

[8] J. Reason, "Human error: models and management," Western Journal of Medicine, vol. 172, no. 6, pp. 393-396, 2000.

[9] S. Rowlinson and Y. A. Jia, "Construction accident causality: an institutional analysis of heat illness incidents on site," Safety Science, vol. 78, pp. 179-189, 2015.

[10] S. W. A. Dekker, "The re-invention of human error," Human Factors and Aerospace Safety, vol. 1, pp. 1153-1155, 2001.

[11] J. Wang, P. X. Zou, and P. P. Li, "Critical factors and paths influencing construction workers' safety risk tolerances," Accident Analysis and Prevention, vol. 93, pp. 267-279, 2016.

[12] D. A. Wiegmann and S. A. Shappell, A Human Error Approach to Aviation Accident Analysis: The Human Factors Analysis and Classification System, Reference and ResearchBook News, Ashgate, Burlington, VT, USA, 2003.

[13] J. Huang, X. Wang, and R. Chen, "Genetic algorithms for optimization of resource allocation in large scale construction project management," Journal of Computers, vol. 5, no. 12, pp. 1916-1924, 2010.

[14] M. M. Khattab and K. Søyland, "Limited-resource allocation in construction projects," Computers and Industrial Engineering, vol. 31, no. 1-2, pp. 229-232, 1996.

[15] M. C. Chiu and M. C. Hsieh, "Latent human error analysis and efficient improvement strategies by fuzzy TOPSIS in aviation maintenance tasks," Applied Ergonomics, vol. 54, no. 9, pp. 136-147, 2016.

[16] H. W. Heinrich, D. Petersen, and N. Roos, Industrial Accident Prevention, McGraw-Hill, New York, NY, USA, 1950. 
[17] D. Oswald, S. Smith, and F. Sherratt, "Accident investigation on a large construction project: an ethnographic case study," Procedia Manufacturing, vol. 3, pp. 1788-1795, 2015.

[18] F. Dongping and Z. Mengchun, "Cognitive causes of construction worker's unsafe behaviors and management measures," China Civil Engineering Journal, vol. 45, no. 2, pp. 197-305, 2012.

[19] I. Donald and S. Young, "Managing safety: an attitudinalbased approach to improving safety in organizations," Leadership and Organization Development Journal, vol. 17, no. 4, pp. 13-20, 1996.

[20] K. Mearns, R. Flin, and R. Gordon, "Risk perception and attitudes to safety by personnel in the offshore oil and gas industry: a review," Journal of Loss Prevention in the Process Industries, vol. 8, no. 5, pp. 299-305, 1995.

[21] J. Reason, Managing the Risks of Organizational Accidents, vol. 43, Burlington, VT, USA, 1997, http://Actoolkit.unprme.org.

[22] S. Chi, S. Han, and D. Y. Kim, "The relationship between unsafe working conditions and workers' behavior and their impacts on injury severity in the U.S," Journal of Construction Engineering and Management, vol. 139, no. 7, pp. 1826-838, 2013.

[23] J. Zuo, R. Rameezdeen, M. Hagger, Z. Zhou, and Z. Ding, "Dust pollution control on construction sites: awareness and self-responsibility of managers," Journal of Cleaner Production, vol. 166, pp. 312-320, 2017.

[24] E. Koningsveld, M. van der Grinten, H. van der Molen, and F. Krause, "A system to test the ground surface conditions of construction sites-for safe and efficient work without physical strain," Applied Ergonomics, vol. 36, no. 4, pp. 441-448, 2005.

[25] A. Suraji, A. R. Duff, and S. J. Peckitt, "Development of causal model of construction accident causation," Journal of Construction Engineering and Management, vol. 127, no. 4, pp. 337-344, 2001.

[26] S. B. Krivit, J. H. Lehr, and T. B. Kingery, "Nuclear energy encyclopedia: science, technology, and applications," Reference Reviews, vol. 27, no. 1, pp. 34-35, 2013.

[27] J. L. Meliá and M. Becerril, "Health behaviour and safety in the construction sector," Psicothema, vol. 21, no. 3, pp. 427-432, 2009.

[28] H. Lingard and S. Rowlinson, "Occupational health and safety in construction project management," Occupational Health and Safety, vol. 65, no. 4, pp. 149-157, 2005.

[29] Y. Khosravi, H. Asilianmahabadi, E. Hajizadeh et al., "Modeling the factors affecting unsafe behavior in the construction industry from safety supervisors' perspective," Journal of Research in Health Sciences, vol. 14, no. 1, pp. 29-35, 2014.

[30] F. Sherratt, S. Smith, and D. Oswald, "Unsafe acts and unsafe conditions: development of a continuum model," in Proceedings of CIB W099 Benefitting Workers and Society through Inherently Safe(r) Construction, pp. 10-11, Belfast, Northern Ireland, September 2015.

[31] Y. S. Yoon, D. H. Ham, and C. Y. Wan, "Application of activity theory to analysis of human-related accidents: method and case studies," Reliability Engineering and System Safety, vol. 150 , pp. 22-34, 2016.

[32] D. C. Krulak, "Human factors in maintenance: impact on aircraft mishap frequency and severity," Aviation Space and Environmental Medicine, vol. 75, no. 5, p. 429, 2004.

[33] M. Celika and S. Cebib, "Analytical HFACS for investigating human errors in shipping accidents," Accident Analysis and Prevention, vol. 41, no. 1, pp. 66-75, 2009.
[34] M. G. Lenné, P. M. Salmon, C. C. Liu, and M. Trotter, “A systems approach to accident causation in mining: an application of the HFACS method," Accident Analysis and Prevention, vol. 48, pp. 111-117, 2012.

[35] M. T. Baysari, A. S. McIntosh, and J. R. Wilson, "Understanding the human factors contribution to railway accidents and incidents in Australia," Accident Analysis and Prevention, vol. 40, no. 5, pp. 1750-1757, 2008.

[36] J. Reason, "A system approach to organizational error," Ergonomics, vol. 38, no. 8, pp. 1708-1721, 1995.

[37] D. A. Wiegmann and S. A. Shappell, "Human error analysis of commercial aviation accidents: application of the Human Factors Analysis and Classification System (HFACS)," Aviation Space and Environmental Medicine, vol. 72, no. 11, pp. 1006-1016, 2001.

[38] A. Hale, D. Walker, N. Walters, and H. Bolt, "Developing the understanding of underlying causes of construction fatal accidents," Safety Science, vol. 50, no. 10, pp. 2020-2027, 2012.

[39] W. C. Li and D. Harris, "Pilot error and its relationship with higher organizational levels: HFACS analysis of 523 accidents," Aviation Space and Environmental Medicine, vol. 77, no. 10, p. 1056, 2006.

[40] A. Kandil and K. El-Rayes, "MACROS: multi-objective automated construction resource optimization system," Journal of Management in Engineering, vol. 22, no. 3, pp. 126-134, 2006.

[41] H. Motulsky, Intuitive Biostatistics, Oxford University Press, Inc., New York, NY, USA, 1995.

[42] N. S. Olsen and S. T. Shorrock, "Evaluation of the HFACSADF safety classification system: intercoder consensus and intracoder consistency," Accident Analysis and Prevention, vol. 42, no. 2, pp. 437-444, 2010.

[43] W. L. Neuman, "Social research methods: qualitative and quantitative approaches," Social Research Methods Qualitative and Quantitative Approaches, vol. 39, no. 3, pp. 447-444, 2011.

[44] S. Reinach and A. Viale, "Application of a human error framework to conduct train accident/incident investigations," Accident Analysis and Prevention, vol. 38, no. 2, pp. 396-406, 2006.

[45] S. T. Chen, A. Wall, P. Davies, Z. Yang, J. Wang, and Y.-H. Chou, "A human and organizational factors (HOFs) analysis method for marine casualties using HFACS-Maritime accidents (HFACS-MA)," Safety Science, vol. 60, no. 12, pp. 105-114, 2013.

[46] A. R. Hale, "Culture's confusions," Safety Science, vol. 34, no. $1-3$, pp. 1-14, 2000.

[47] E. A.-L. Teo and Y. Feng, "The role of safety climate in predicting safety culture on construction sites," Architectural Science Review, vol. 52, no. 1, pp. 5-16, 2009.

[48] E. Schein, "Organizational culture," American Psychologist, vol. 45, no. 2, pp. 109-119, 1990.

[49] D. A. Wiegmann, H. Zhang, T. L. Haden, G. Sharma, and A. M. Gibbons, "Safety culture: an integrative review," International Journal of Aviation Psychology, vol. 14, no. 2, pp. 117-134, 2004.

[50] Advisory Committee for the Safety of Nuclear Installations (ACSNI), Human Factors Study Group Third Report: Organizing for Safety, Health and Safety Executive (HSE) Books, Sheffield, UK, 1993.

[51] I. M. Shohe and A. Laufer, "What does the construction foreman do?" Construction Management and Economics, vol. 9, no. 6, pp. 565-576, 1991. 
[52] C. Kim, T. Park, H. Lim, and H. Kim, "On-site construction management using mobile computing technology," Automation in Construction, vol. 35, no. 2, pp. 415-423, 2013.

[53] B. Kirwan, "Safety informing design," Safety Science, vol. 45, no. 1-2, pp. 155-197, 2007.

[54] P. C. Cacciabue and G. Vella, "Human factors engineering in healthcare systems: the problem of human error and accident management," International Journal of Medical Informatics, vol. 79, no. 4, pp. 1-17, 2010.

[55] A. Charehzehi and A. Ahankoob, "Enhancement of safety performance at construction site," International Journal of Advances in Engineering and Technology, vol. 5, no. 1, 2012.

[56] C. Qingren, L. Kai, and L. Jinglin, "Impact of manager's behavior on coalminer's unsafe behavior impact of manager's behavior on coalminer's unsafe behavior," Journal of Management Science, vol. 24, no. 6, pp. 69-78, 2011.

[57] A. N. Yong-Lin, H. Kan, and L. M. Peng, "Risk assessment on man-machine-environment system of tunnel construction," Journal of Central South University, vol. 43, no. 1, pp. 301-307, 2012.

[58] X. Song and Z. Xie, "Application of man-machineenvironment system engineering in coal mines safety management," Procedia Engineering, vol. 84, no. 2, pp. 87-92, 2014.

[59] H. M. Tiesman, C. Peek-Asa, P. Whitten, N. L. Sprince, A. Stromquist, and C. Zwerling, "Depressive symptoms as a risk factor for unintentional injury: a cohort study in a rural county," Injury Prevention, vol. 12, no. 3, p. 172, 2006.

[60] L. Zheng, H. Xiang, X. Song, and Z. Wang, "Nonfatal unintentional injuries and related factors among male construction workers in central China," American Journal of Industrial Medicine, vol. 53, no. 6, p. 588, 2010.

[61] L. M. Goldenhar, L. J. Williams, and N. G. Swanson, "Modelling relationships between job stressors and injury and near-miss outcomes for construction laborers," Work and Stress, vol. 17, no. 3, pp. 218-240, 2003.

[62] W. Binhai, "Distinctions between spirit and psychology," Journal of Liuzhou Vocational and Technical College, vol. 4, no. 4, pp. 118-124, 2004.

[63] G. I. Popov, M. P. Hristova, and H. A. Hristov, "Safety modeling of the man-machine interface in railway signaling systems," in Proceedings of International Conference on Mathematical MODELS for Engineering Science. World Scientific and Engineering Academy and Society (WSEAS), pp. 159-163, Beijing, China, July 2010.

[64] R. M. Choudhry and F. Dongping, "Why operatives engage in unsafe work behavior: investigating factors on construction sites," Safety Science, vol. 46, no. 4, pp. 566-584, 2008.

[65] T. Aksorn and B. H. W. Hadikusumo, "Critical success factors influencing safety program performance in Thai construction projects," Safety Science, vol. 46, no. 4, pp. 709-727, 2008.

[66] J. M. Patterson and S. A. Shappell, "Operator error and system deficiencies: analysis of 508 mining incidents and accidents from Queensland, Australia using HFACS," Accident; Analysis and Prevention, vol. 42, no. 4, p. 1379, 2010.

[67] O. Soner, U. Asan, and M. Celik, "Use of HFACS-FCM in fire prevention modelling on board ships," Safety Science, vol. 77, pp. 25-41, 2015.

[68] W. G. Cochran, "The comparison of percentages in matched samples," Biometrika, vol. 37, no. 3-4, p. 256, 1950.

[69] J. Reason, Human Error, Cambridge University Press, Cambridge, UK, 1990.

[70] W. C. Li, D. Harris, and C. S. Yu, "Routes to failure: analysis of 41 civil aviation accidents from the Republic of China using the human factors analysis and classification system," Accident Analysis and Prevention, vol. 40, no. 2, pp. 426-434, 2008.

[71] A. W. F. Edwards, "The measure of association in a $2 \times 2$ table," Journal of the Royal Statistical Society, vol. 126, no. 1, pp. 109-114, 1963.

[72] Y. Feng, "Effect of safety investments on safety performance of building projects," Safety Science, vol. 59, pp. 28-45, 2013.

[73] M. Yu, L. Y. Sun, and C. Egri, "Workplace safety climate assessment based on behaviors and measurable indicators," Process Safety Progress, vol. 27, no. 3, pp. 239-247, 2008.

[74] J. U. Schröderhinrichs, M. Baldauf, and K. T. Ghirxi, "Accident investigation reporting deficiencies related to organizational factors in machinery space fires and explosions," Accident Analysis and Prevention, vol. 43, no. 3, pp. 11871196, 2011.

[75] P. A. S. Mendes, J. Hall, S. Matos, and B. Silvestre, "Reforming Brazil's offshore oil and gas safety regulatory framework: lessons from Norway, the United Kingdom and the United States," Energy Policy, vol. 74, pp. 443-453, 2014.

[76] D. R. Kouabenan, R. Ngueutsa, and S. Mbaye, "Safety climate, perceived risk, and involvement in safety management," Safety Science, vol. 77, pp. 72-79, 2015.

[77] N. A. Stanton, P. M. Salmon, and D. P. Jenkins, Human Factors in the Design and Evaluation of Central Control Room Operations, Taylor \& Francis, Boca Raton, FL, USA, 2009.

[78] F. Zhang, J. Zuo, and G. Zillante, "Identification and evaluation of the key social competencies for Chinese construction project managers," International Journal of Project Management, vol. 31, no. 5, pp. 748-759, 2013.

[79] C. A. Wenner and C. G. Drury, "Analyzing human error in aircraft ground damage incidents," International Journal of Industrial Ergonomics, vol. 26, no. 2, pp. 177-199, 2000. 


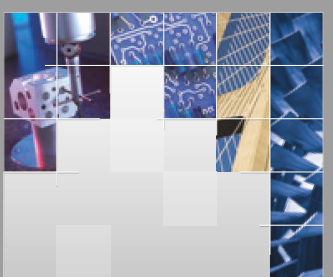

\section{Enfincering}
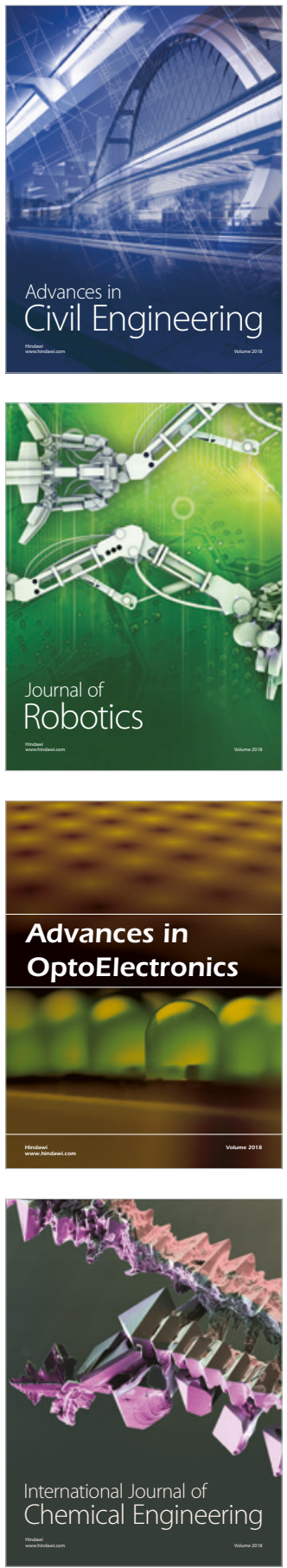

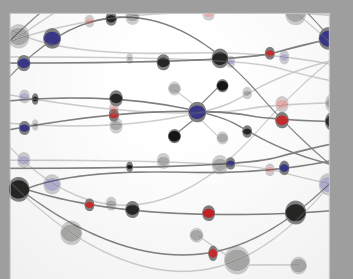

\section{Rotating \\ Machinery}

The Scientific World Journal

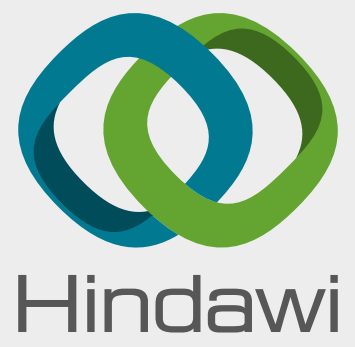

Submit your manuscripts at

www.hindawi.com
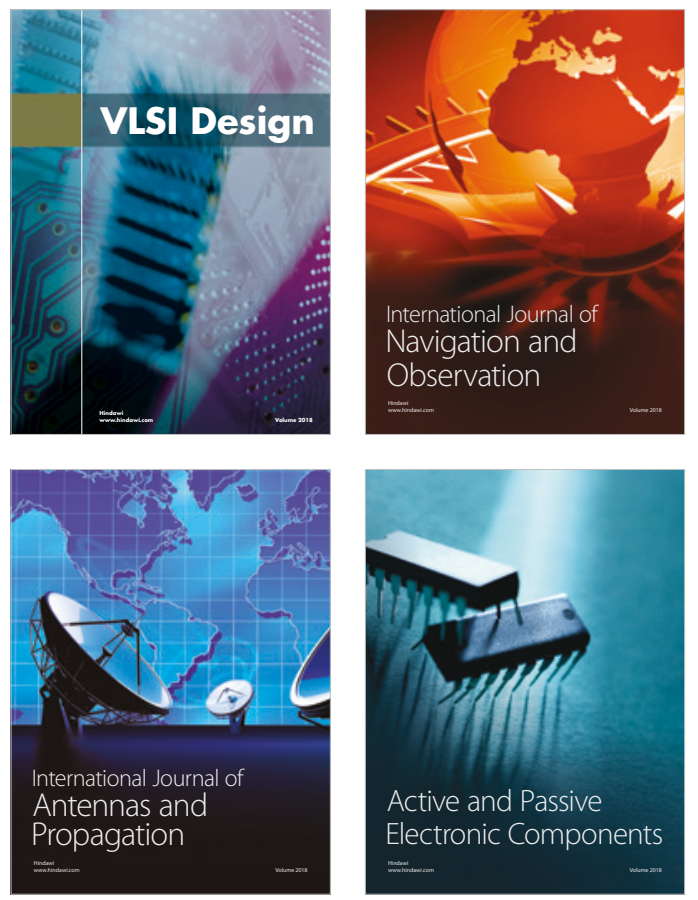
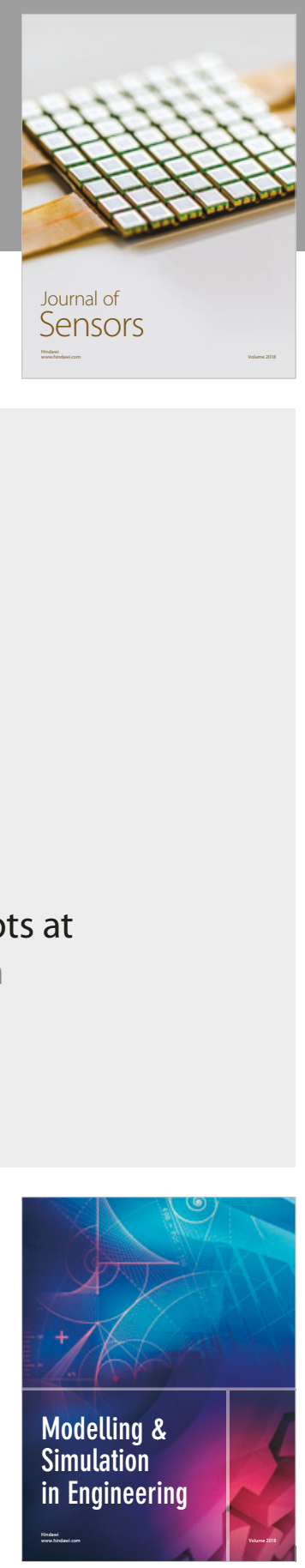

\section{Advances \\ Multimedia}
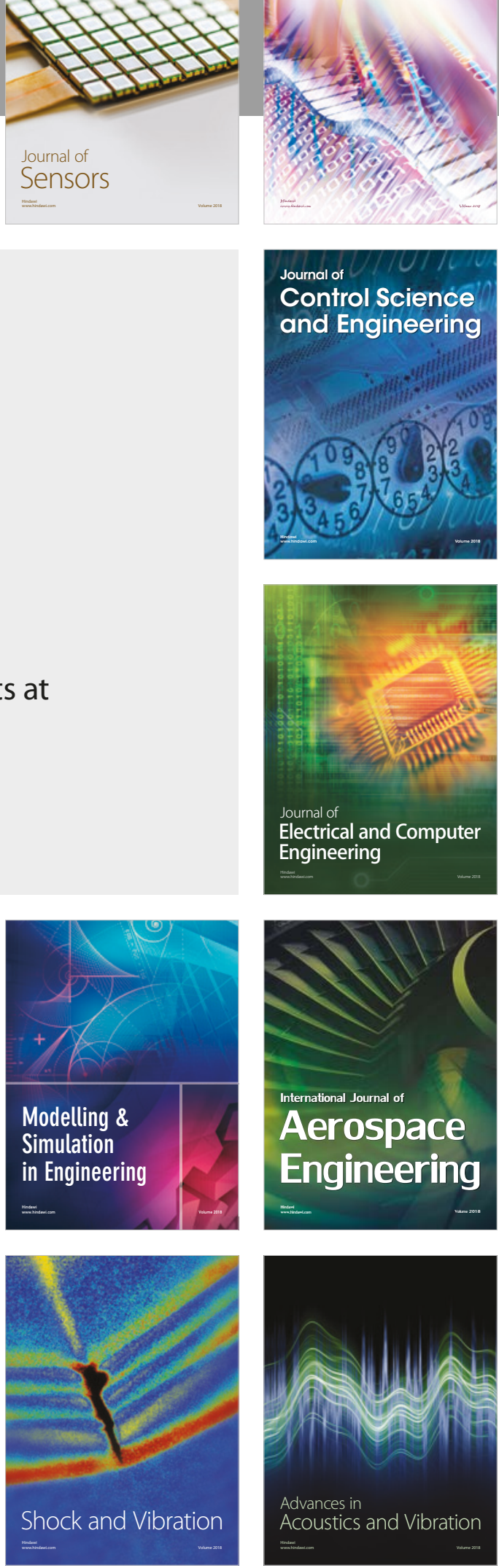